\section{Persistence of miracles}

SIR - A leading article in Nature (19 July, p. 171), quite rightly questioned whether "science has nothing to say" on the subject of miracles; but it was surely wrong in attributing to science the dogma that "'miracles do not occur". In scientific laws we describe, as best we can, the pattern of precedent we observe in the sequence of natural events. While our laws do not prescribe what must happen, they do prescribe what we ought to expect on the basis of precedent. If by a "miracle" we mean an unprecedented event (and the resurrection of Christ is certainly described as such), then science says that miracles ought not to be expected on the basis of precedent. What science does not (and cannot) say, of course, is that the unprecedented does not (or cannot) occur.

If, as Christians have traditionally believed, the whole spatio-temporal sequence of events that make up our world owes its being to our Creator, then it is thanks to Him that our scientific explanations normally prove as reliable as they do. But by the same token, nothing whatever in our observations of "normal precedent" can make it impossible for the Creator to bring about a totally unprecedented event, if His overall purpose for His creation requires it. Christians believe that the resurrection of Christ was just such an event. We do no good to the cause of science by pretending that there are scientific grounds for denying that it could have happened.

To say this, however, is not to suggest that we should go soft on "mischievous reports of all things paranormal, from ghosts to flying saucers", as Nature's leader writer seemed to fear. For the Christian believer, baseless credulity is a sin - a disservice to the God of truth. His

\section{BioNet and GenBank}

SIR - A few points in your recent news article "Limited access to BioNet" (30 August, p. 717) require clarification. The article confuses two separate projects funded by the US Government: the GenBank project, which is the national genetic sequence data bank in the United States funded by several institutes of the National Institutes of Health (NIH) and other government agencies; and BioNet, a computing resource for molecular biologists also supported by NIH.

GenBank is a contract jointly run by the Los Alamos National Laboratory and Bolt Beranek and Newman, Inc. to collect, maintain, distribute and provide computer access to nucleic acid sequences and related data. It is this work which is performed in close collaboration with the parallel effort here at EMBL in Heidelberg. The task of data collection is in fact shared between the belief in the resurrection does not stem from softness in his standards of evidence, but rather from the coherence with which (as he sees it) that particular unprecedented event fits into and makes sense of a great mass of data. Some of these data are historical, some derived from the cumulative experience of Christians down the ages, including himself. So his faith is not groundless. There is clearly no inconsistency in believing (with astonishment) in a unique event so well attested, while remaining unconvinced by spectacular stories of "paranormal" occurrences that lack any comparable support.

Both wishful thinking and wishful unthinking are evils, and it will not do to tumble into one for fear of the other. We cannot dogmatically exclude the everpresent possibility that the truth about our world is stranger than we have imagined.

DONALD M. MACKAY

Department of Communications

and Neuroscience,

University of Keele,

Keele, Staffordshire ST5 5BG, UK

SIR - Your leading article "Miracles do not happen"' (Nature 19 July, p.171) appears to contradict itself at least twice. First you urge critical rigour for evaluating a particular miracle, the turning of water into wine by Jesus. I agree. But then you baldly state: "Miracles... do not occur - a definition by exclusion of the concept". You apparently mean that they are excluded from all factual discourse, not just from science, since the latter would be agreeing with the very notion you wish to oppose that science has nothing to say about miracles. Finally, you state that religious

EMBL and GenBank groups, and data are exchanged on a regular and unrestricted basis.

BioNet is a project managed by Intelligenetics, Inc. to provide molecular biologists with computing resources, including analysis software, communications facilities, and databases accessible by computer network. (Two of the databases so provided are those produced by the GenBank and EMBL efforts.) Limitations on BioNet access are necessary because it is, at present, implemented on a single computer of finite capacity.

It should be stressed that these limitations apply to use of the BioNet computing facility, not to availability of the GenBank and EMBL' databases. Both databases are available worldwide, in various forms, to anyone.

GREG H. HAMM

European Molecular Biology Laboratory, Postfach 10.2209,

Meyerhofstrasse 1,

6900 Heidelberg, FRG belief "on other grounds" is unexceptionable.

But why insist on critical rigour for evaluating particular miracles, if by definition they do not occur? And how can you find religious belief "unexceptionable" if you deny (by definition!) some of its key tenets. It is not only the grounds of belief that are at issue here, but the content.

Your concern not to license "mischievous reports of all things paranormal" is no doubt motivated in the interest of scientific truth, but your strategy of defining away what you find unpalatable is the antithesis of scientific. It is disheartening that Nature should sell its empiricist birthright for the stale soup of a priori rationalism.

P.G.H. Clarke

Institut d'Anatomie,

Rue du Bugnon 9,

1011 Lausanne, Switzerland.

SiR - Jeremy Marshall (Nature 30 August, p. 722) would like scientists to behave themselves and stop questioning miracles, as a sort of act of gratitude for his consent to "believe that evolution has occurred". He objects to scientists concerning themselves with miracles because this subject "is outside the bounds of proper scientific inquiry".

Unfortunately, miracles are sometimes invoked to explain natural phenomena on a nonscientific basis. Creationists have been particularly adept in the use of this device. Conclusions about miracles have been repeatedly reached by scientists on a scientific basis, and are not necessarily an invasion of theology. In turn, scientific inquiry into natural phenomena often reveals facts that seem sufficiently miraculous to excite admiration and awe from scientists and theologians alike.

THOMAS H. JUKES

University of California,

Berkeley, California 94720, USA

\section{Nuclear power}

SIR - J.R. Ravetz complains (Nature 9 August, p. 446) that Nuclear Power Technology, reviewed by Sir Alan Cottrell (Nature 309, 545; 1984), contains no reference to weapons technology. As deputy editor of that book I should explain that it is about nuclear power technology, not nuclear weapons technology.

While nuclear power stations and some nuclear weapons draw their energy from the same fundamental phenomenon, namely nuclear fission, the staff of the Atomic Energy Authority, by whom the material for the book was written, are not competent to write about nuclear weapons.

I am sure Mr Ravetz would not expect to see high explosives technology discussed in a book on oil-fired power stations, although the energy source is common to both. R. H. FLOWERS

Fuel Processing Directorate,

UK Atomic Energy Authority,

Harwell, Oxon OXI1 ORA, UK 